\title{
Hypoxia-inducible factors in hepatocellular carcinoma (Review)
}

\author{
YANG GUO $^{1 *}$, ZUNQIANG XIAO $^{2 *}$, LIU YANG $^{3}$, YULING GAO $^{4}$, QIAOJUAN ZHU ${ }^{2}$, \\ LINJUN HU ${ }^{5}$, DONGSHENG HUANG ${ }^{3}$ and QIURAN XU ${ }^{3}$
}

\author{
${ }^{1}$ Graduate Department, BengBu Medical College, Bengbu, Anhui 233030; ${ }^{2}$ The Second Clinical Medical Department, \\ Zhejiang Chinese Medical University; ${ }^{3}$ The Key Laboratory of Tumor Molecular Diagnosis and Individualized Medicine of \\ Zhejiang Province, Zhejiang Provincial People's Hospital (People's Hospital of Hangzhou Medical College), \\ Hangzhou, Zhejiang 310014; ${ }^{4}$ Department of Genetics, Shaoxing Women and Children Hospital, Shaoxin, \\ Zhejiang 312030; ${ }^{5}$ Medical Department, Qingdao University, Qingdao, Shandong 266071, P.R. China
}

Received April 25, 2019; Accepted August 16, 2019

DOI: 10.3892/or.2019.7397

\begin{abstract}
Maintenance of an appropriate oxygen concentration is essential for the function of the liver. However, in many pathological conditions, and particularly in the tumor microenvironment, cells and tissues are frequently in a hypoxic state. In the presence of hypoxia, the cells adapt to the low oxygen levels through the hypoxia-inducible factor (HIF) pathway. Overgrowth of tumor cells restricts the diffusion of oxygen in tumors, leading to insufficient blood supply and the creation of a hypoxic microenvironment, and, as a consequence, activation of the expression of HIFs. HIFs possess a wide range of target genes, which function to control a variety of signaling pathways; thus, HIFs modulate cellular metabolism, immune escape, angiogenesis, metastasis, extracellular matrix remodeling, cancer stem cells and other properties of the tumor. Given their crucial role in the occurrence and development of tumors, HIFs are expected to become new targets of precise treatment of hepatocellular carcinoma.
\end{abstract}

\section{Contents}

1. Introduction

2. Structure and function of HIFs

3. Expression of HIF in HCC and their association with clinical outcomes

Correspondence to: Dr Dongsheng Huang or Dr Qiuran Xu, The Key Laboratory of Tumor Molecular Diagnosis and Individualized Medicine of Zhejiang Province, Zhejiang Provincial People's Hospital (People's Hospital of Hangzhou Medical College), 158 Shangtang Road, Hangzhou, Zhejiang 310014, P.R. China

E-mail: dshuang@zju.edu.cn

E-mail: windway626@sina.com

${ }^{*}$ Contributed equally

Key words: hypoxia-inducible factor, hypoxia, glucose transporter, immune escape, metastasis
4. Relationship between HIF and HCC
5. Metabolism
6. Immune escape
7. Angiogenesis
8. Metastasis
9. Extracellular matrix remodeling
10. Cancer stem cells
11. HIF- $1 \alpha$ as a therapeutic target
12. Conclusions and future perspectives

\section{Introduction}

Hepatocellular carcinoma (HCC) is one of the most common malignant tumors of the digestive system.In2015,466,100 patients were newly diagnosed with HCC in China, and the number of deaths caused by HCC deaths was 422,100 (1). In China, HCC is one of the four major causes of cancer-related deaths. HCC is a hypermetabolic tumor that consumes more oxygen than the surrounding normal tissues. However, the uncontrolled proliferation of HCC cells leads to an insufficient oxygen supply and the rapidly growing tumor not only quickly consumes oxygen but also lacks adequate vascularization, subsequently generating a hypoxic microenvironment. Hypoxia-inducible factors (HIFs) are recognized as crucial transcriptional regulators that are activated under hypoxia (2). A number of recent studies have documented the involvement of HIFs in HCC cell proliferation, angiogenesis, invasion and metastasis $(3,4)$. In addition, progress has been made in the development of HCC therapies involving the targeting HIFs (5). Currently, the research on HIFs is focused on two aspects, the mechanism of transcriptional regulation of HIFs and cancer therapy targeting HIFs. Therefore, the present review examined the processes of regulation and activation of HIFs in HCC, and focused on the progress of research on the function of HIFs in HCC.

\section{Structure and function of HIFs}

The rapid proliferation of cancer cells leads to the rapid consumption of tissue oxygen. When the rate of oxygen consumption exceeds the rate of oxygen supply by the 
circulation, hypoxia develops (2). A hypoxic state activates a series of adaptive responses of cells, which are primarily mediated by HIFs. The human genome encodes three different HIF subtypes: HIF-1 $\alpha$, HIF- $2 \alpha$ and HIF-3 $\alpha$ (Fig. 1). HIFs are heterodimers composed of a functional $\alpha$ subunit and a stably expressed $\beta$ subunit (6). The N-terminus of HIFs has a basic helix-loop-helix (bHLH) domain and a Per-ARNT-Sim (PAS) domain that participate in the heterodimerization of the $\alpha$ and $\beta$ subunits. These domains also mediate HIF binding to the hypoxia response element (HRE) in a target gene promoter. The C-terminus of HIF proteins includes two transactivation domains (TAD), an N-terminal (N)-TAD and a C-terminal (C)-TAD. The N-TAD domain serves an essential function in activating HIF- $1 \alpha$ or HIF-2 $\alpha$ target genes; N-TAD is the major transactivation domain responsible for HIF- $1 \alpha$ or HIF- $2 \alpha$ target gene specificity; as a transcriptional activation domain, N-TAD may serve as an important cofactor for interaction sites. Transcriptional cooperation between HIF-1 $\alpha$ and certain factors (such as SMAD3/4 and ETS-1) can induce activation of multiple HIF target genes under hypoxic conditions (7). The C-TAD acts to recruit p300/CREB-binding protein (CBP) and other auxiliary transcription factors. In addition, the structure of HIFs includes an oxygen-dependent degradation domain (ODDD), which overlaps with N-TAD, but its function is different from N-TAD. The ODDD serves as the recognition site of the von Hippel-Lindau tumor suppressor protein (pVHL) and is involved in the stabilization of proteins and the regulation of intracellular oxygen concentration. The $\beta$ subunit is constitutively expressed, it is not regulated by intracellular oxygen concentration, and does not have transcriptional activity alone; only a heterodimer of HIF- $\alpha$ and HIF- $\beta$ subunits is active. The ODDD contains two proline residues that can be hydroxylated by the prolyl hydroxylase domain (PHD) enzymes. Hydroxylated HIF subtypes are recognized by pVHL, which is ubiquitinated by pVHL-related elongin BC-Cul2 ubiquitin ligase complex. Hydroxylated HIF-1 $\alpha$ binds to pVHL, which recruits elongin B, elongin C, cullin-2 and loop cassette 1 to form the E3 ubiquitin ligase complex. Unlike the targeted proteasomal degradation, HIF-1 $\alpha$ forms the E3 ubiquitin ligase complex, which ubiquitinates HIF-1 $\alpha$ and is ultimately mediated by the $26 \mathrm{~S}$ proteasome (8-10), whereas HIF- $2 \alpha$ is ubiquitinated by the of $\mathrm{E} 2$ ubiquitin-binding enzyme; but, both HIF- $1 \alpha$ and HIF- $2 \alpha$ are subsequently degraded by $26 \mathrm{~S}$ proteasome (8).

PHDs are key enzymes of this degradation process, which uses oxygen and 2-ketoglutarate as substrates, and $\mathrm{Fe}^{2+}$ and ascorbate as co-factors of dioxygenase (Fig. 2). The activity of HIFs can also be suppressed by the HIF-1 inhibitor, such as factor inhibiting HIF-1 $\alpha$ (FIH-1). The catalytic effect of FIH-1 is similar to that of PHD, which also requires oxygen and 2-ketoglutarate as substrates. Factor inhibiting HIF-1 $\alpha$ (FIH) is an asparaginyl hydroxylase that catalyzes the hydroxylation of asparagine 803 (Asn803) on C-TAD, preventing HIF-1 $\alpha$ from interacting with $\mathrm{p} 300 / \mathrm{CBP}$ and inhibiting its transcriptional activity. However, both PHDs and HIFs are oxygen-dependent and, therefore, are inactive under hypoxic conditions, forming stable aggregates of HIF subtypes in the cytoplasm $(11,12)$. Additionally, PHD activity can be inhibited by numerous important metabolites, including reactive oxygen species (ROS), nitric oxide (NO), succinate and fumarate (13).
By contrast, cysteine may enhance PHD2 activity by inhibiting autoxidation (14).

HIF expression can also be regulated by other factors, including growth factors such as platelet-derived growth factor (PDGF), insulin-like growth factor 1 (IGF-1), insulin and heregulin (Fig. 2). The Akt/HIF-1a/PDGF-BB autocrine signaling loop is formed under hypoxic conditions to increase the chemosensitivity of liver cancer cells (15). Previous studies have shown that IGF-1 affects HIF- $1 \alpha$ and HIF- $2 \alpha$ protein synthesis $(16,17)$. Insulin regulates HIF-1 $\alpha$ by a ROS-sensitive activation of Sp1 in 3T3-L1 preadipocytes (18); this is a novel transcriptional mechanism by which insulin is involved in Sp1. Heregulin stimulates HIF-1 $\alpha$ synthesis via a rapamycin-dependent manner (19). Acetyltransferases can acetylate the lysine residue at position 532 of HIF-1 $\alpha$, enhancing the binding ability of pVHL to HIF-1 $\alpha$ and, ultimately, promoting its degradation (20). Receptor for activated protein C kinase 1 (RACK1) and heat shock protein 90 (Hsp90) compete to bind to the PAS region of HIF-1 $\alpha$; RACK1 enhances the binding of HIF-1 $\alpha$ to E3 ligase and promotes degradation, whereas Hsp90 stabilizes HIF- $1 \alpha$ and prevents its degradation (Fig. 2) (21).

The expression and activity of HIF-2 $\alpha$ are also regulated by certain non-oxygen-dependent pathways, such as small ubiquitin-related modifier (SUMO) modification. SUMO modification is the main mechanism of HIF- $2 \alpha$ degradation under hypoxia, which can negatively regulate the expression of HIF- $2 \alpha$. HIF- $2 \alpha$ binds covalently to SUMO-2 via Lys394, resulting in its modification by SUMO.SUMO-modified HIF- $2 \alpha$ is degraded by a mechanism involving SUMO-dependent E3 ubiquitin-protein ligase RNF4 and pVHL (Fig. 2) (22).

Although numerous studies have focused on HIF-1 $\alpha$ and HIF- $2 \alpha$, our understanding of the role of HIF- $3 \alpha$ in cancer cells is limited (23). It has been reported that HIF-3 $\alpha$ can also be activated under hypoxic conditions and regulate the transcription and protein stability of HIF-1 $\alpha$ (24-26). In addition, HIF-3 $\alpha$ can activate the transcription of a set of specific target genes, which partially overlaps with genes upregulated by HIF- $1 \alpha$ and HIF- $2 \alpha$, but their role remains to be demonstrated in future studies (27-29).

\section{Expression of HIFs in HCC and their association with clinical outcomes}

A large number of clinical studies have demonstrated a relationship between HIFs and metastasis, recurrence, vascular proliferation and prognosis of patients with HCC (Table I). The data indicate that the expression of HIF-1 $\alpha$ in HCC tissues was higher compared with that in corresponding adjacent tissues. Overexpression of HIF-1 $\alpha$ is associated with poor prognosis in patients with HCC; however, some recent studies have not reported that expression of HIF-2 $\alpha$ or HIF- $3 \alpha$ in HCC is associated with prognosis (Table I).

\section{Relationship between HIF and HCC}

A number of previous studies have demonstrated a complex relationship between HIF and HCC $(30,31)$. The relationship between HIFs and HCC include, metabolism, immune escape, angiogenesis, metastasis, extracellular matrix (ECM) remodeling and activity of cancer stem cells (CSCs) (Fig. 3). 


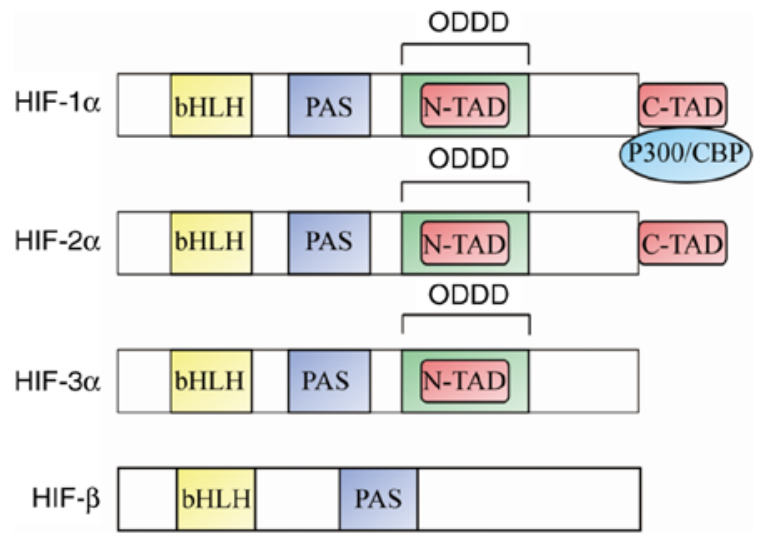

Figure 1. Structure of HIFs and functional domains. HIF-1 $\alpha$ and HIF-2 $\alpha$ are highly similar in amino acid sequence, and both contain bHLH, PAS and TAD functional domains (C-TAD and N-TAD), among which C-TAD is enriched with various auxiliary transcription factors such as p300/CBP HIF- $3 \alpha$ contains only bHLH, PAS and N-TAD. Furthermore, the HIF- $1 \alpha$, HIF- $2 \alpha$ and HIF- $3 \alpha$ structures include the ODDD domain, which acts as a recognition site for the tumor suppressor protein pVHL and is involved in protein stabilization and regulation of intracellular oxygen concentration HIF- $\beta$ contains bHLH and PAS, and the HIF- $\beta$ subunit is not regulated by intracellular oxygen concentration and has no transcriptional activity alone; only heterodimers of HIF- $\alpha$ and $-\beta$ subunits are active. bHLH, basic helix-loop-helix; C, carboxy-terminus; CBP, CREB-binding protein; HIF hypoxia-inducible factor; $\mathrm{N}$, amino-terminus; ODDD, oxygen-dependent degradation domain; PAS, Per-ARNT-Sim; pVHL, von Hippel-Lindau tumor suppressor; TAD, transactivation domain; $\mathrm{p} 300 / \mathrm{CBP}$, auxiliary transcription factor.

\section{Metabolism}

The rapid proliferation of cancer cells requires a large amount of energy, resulting in increased consumption of oxygen, which leads to the generation of a hypoxic environment in the tumor tissue. Under hypoxia, tumor cells undergo a transition from aerobic to anaerobic metabolism. This difference in metabolism between normal and cancer cells was first identified in 1920 (32). Normal cells under physiologic oxygen concentration convert glucose into pyruvate, which is further metabolized in the mitochondria via the tricarboxylic acid cycle and oxidative phosphorylation. In these cells, the availability of oxygen inhibits the rate of glycolysis (Pasteur effect), enables mitochondrial respiration, increases ATP levels and inhibits the activity of phosphofructokinase (PFK) responsible for glycolysis (33). Under hypoxic conditions, the final product of anaerobic glycolysis is pyruvic acid, which is subsequently metabolized to lactic acid. In comparison with non-malignant tissues, tumor cells rely more on the use of glycolysis to support their energy needs, even when oxygen is available, a phenomenon called the Warburg effect (34). Tumor cells are known to produce energy by generating ATP in anaerobic glycolysis, a process mainly regulated by HIF- $1 \alpha(35,36)$. HIF- $1 \alpha$ accelerates the glycolysis pathway of cancer cells by activating related target genes and transcription products. This activation may occur through three distinct mechanisms.

The first mechanism, the metabolism of HCC, is often related to the Warburg effect, involves HIF-1 activation of key enzymes involved in glucose metabolism and glycolysis $(37,38)$. Overexpression of HIF- $1 \alpha$ in cancer cells increases the activities of several isoenzymes that are different from those in normal tissues, including adenylate kinase 3 (AK3), aldolase-A (ALD-A) and ALD-C, carbonic anhydrase 9 (CA9), enolase 1 (ENO1), glucose transporter (GLUT)-1 and GLUT-3, GAPDH, hexokinase (HK)-1 and HK2, L-lactate dehydrogenase A chain (LDHA), liver-type PKF (PFKL), phosphoglycerate kinase 1 (PGK1) and 6-phosphofructo-2-kinase/fructose-2,6-bisphosphate 3 (PFKFB3) (Fig. 3).

In the second mechanism, induction of glucose transporter regulation, HIF- $1 \alpha$ induces overexpression and increased activity of several glycolytic protein isoforms, including GLUT1 and GLUT3. HIF1 $\alpha$-induced glucose transport is important for glycolytic flux control and provides new therapeutic targets for inhibiting HCC growth and progression (Fig. 3) (39).

Transcriptional activity of HIF-1, in the third mechanism, increases the expression of mitochondrial-related enzymes, such as pyruvate dehydrogenase kinase 1 (PDK1), which can inhibit the conversion of pyruvate to acetyl coenzyme A and, as a result, reduce the level of oxidative phosphorylation and oxygen consumption by the mitochondria (Fig. 3) (40).

In addition to the above mechanisms, HIF-1 $\alpha$ can reduce intracellular $\mathrm{pH}$ by promoting anaerobic glycolysis and increasing the concentration of lactic acid increase (41). Compared with normal tissues, GLUT1, LDHA, HK1, pyruvate kinase PKM2 and voltage-dependent anion-selective channel protein 1 (VDAC-1) expression levels were revealed to be significantly higher in primary HCC tissues and its metastases (42).

\section{Immune escape}

Progression and metastasis of tumors can take place only if both primary and metastatic tumors have the ability to escape immune surveillance. Numerous studies have demonstrated that hypoxia and HIFs are associated with the evasion of immune response by tumor cells $(43,44)$. The function of immune cells is regulated by HIF1-dependent signaling mechanisms. During hypoxia, HIFs induce the resistance of tumor cells to CD8 cytotoxic T lymphocytes (CTL) and natural killer (NK) cells. The mechanisms involved include inhibition of apoptosis (45) and activation of autophagy (46). Additionally, hypoxia can upregulate the expression of extracellular enzymes CD39 and CD73 that produce adenosine, increasing its concentration in the cell environment. Adenosine strongly inhibits the anti-tumor function of activated $\mathrm{T}$ cells and NK cells by binding to its A2A receptor (47). HIFs can also suppress the immune response against the tumor by acting on the macrophages, so-called tumor-associated macrophages (TAMs), infiltrating the tumor microenvironment (48). TAMs have been repeatedly demonstrated to promote the growth, invasion and metastasis of tumor cells by secreting cytokines such as interleukin (IL)-10, transforming growth factor $\beta$ (TGF- $\beta$ ), IL-6, VEGF and IL-8, as well as matrix metalloproteinases (MMPs) (Fig. 3). The cytokines and MMPs stimulate the tumor cell proliferation, epithelial-mesenchymal transition (EMT), induce neovascularization, promote remodeling of the ECM and inhibit the anti-tumor immune function of the organism (49). In patients with HCC, TAM infiltration in the liver tissue around the tumor has been associated with poor prognosis (50). It has also been 


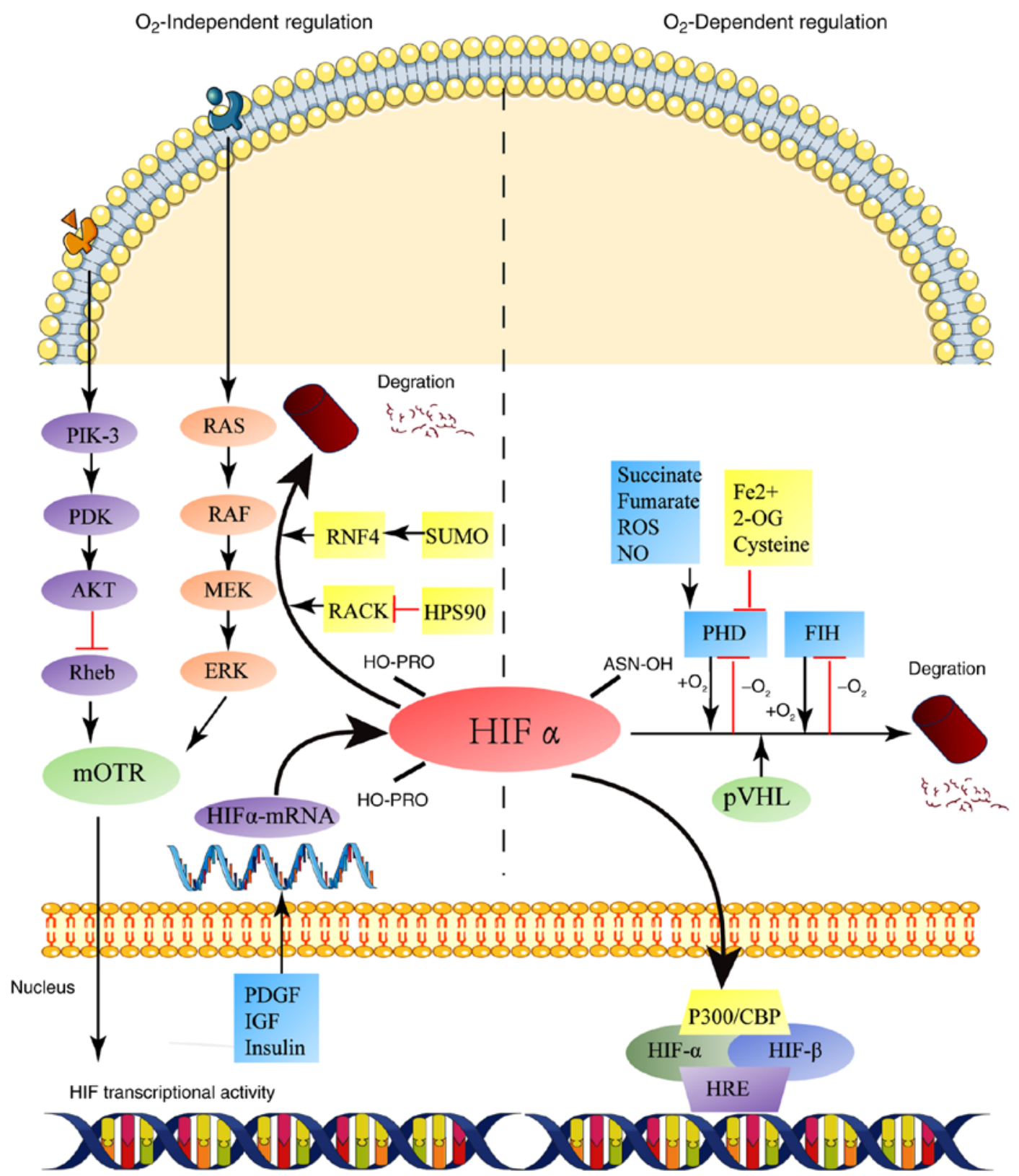

Figure 2. $\mathrm{O}_{2}$-dependent and $\mathrm{O}_{2}$-independent regulation of HIF-1 $\alpha$. At normal oxygen levels $\left(+\mathrm{O}_{2}\right)$, prolyl hydroxylase domain proteins hydroxylate two proline residues of HIF $\alpha$. pVHL recognizes hydroxylated HIF $\alpha$ and mediates proteasomal degradation. Additionally, FIH hydroxylates the asparagine residue of $\mathrm{HIF} \alpha$, inhibiting its interaction with transcriptional coactivator p300/CBP. Conversely, the hydroxylation and degradation of HIF $\alpha$ is inhibited under hypoxia $\left(-\mathrm{O}_{2}\right)$, which transfers HIF $\alpha$ to the nucleus, dimerizes with HIF $\beta$, and interacts with P300/CBP transcriptional activator to bind to target gene initiation and HRE and upregulate its expression. 2-OG, 2-oxyglutarate; ASN-OH, hydroxylated asparagine; CBP, CREB-binding protein; FIH, factor inhibiting HIF-1 $\alpha$; HIF, hypoxia-inducible factor; HRE, hypoxia response element; Hsp90, heat shock protein 90; HO-PRO, hydroxylated proline; IGF, insulin-like growth factor; MEK, MAPK/ERK kinase; NO, nitric oxide; PDGF, platelet-derived growth factor; PDK, pyruvate dehydrogenase kinase; pVHL, von Hippel-Lindau tumor suppressor protein; RACK, receptor for activated protein C kinase; Rheb, Ras homolog enriched in brain; RNF4, E3 ubiquitin-protein ligase RNF4; ROS, reactive oxygen species; SUMO, small ubiquitin-related modifier.

reported that in late-stage $\mathrm{HCC}$, a large number of triggering receptor expressed on myeloid cells 1 (TREM-1)-positive TAMs indirectly affect the cytotoxic function of $\mathrm{CD} 8^{+} \mathrm{T}$ cells and trigger their apoptosis (51). A previous study demonstrated that specific scavenging of macrophages with chlorophosphate liposomes resulted in significant suppression of tumor growth and angiogenesis (52). The role of TAMs was also documented in a study in which their inhibition delayed the growth of HCC in nude mice (53). The role of macrophages in HCC was also underscored by the demonstration that expression of hypoxia-induced high mobility group box-1 protein (HMGB1) promotes tumor invasion and metastasis in animal models of HCC by regulating macrophage-derived IL-6 (54). A previous study demonstrated that hypoxia promotes the immunosuppressive phenotype of $\mathrm{HCC}$ cell lines through upregulation of HIF1-dependent C-C motif chemokine 20 (CCL20) expression, and CCL20 significantly induces indoleamine 2,3-dioxygenase (IDO) expression in monocyte-derived macrophages (55). This study also showed a link between elevated CCL20 levels and poor survival in patients with liver cancer, suggesting a link between microenvironment of immunosuppressive hypoxic tumors and promotion of metastasis (55). 


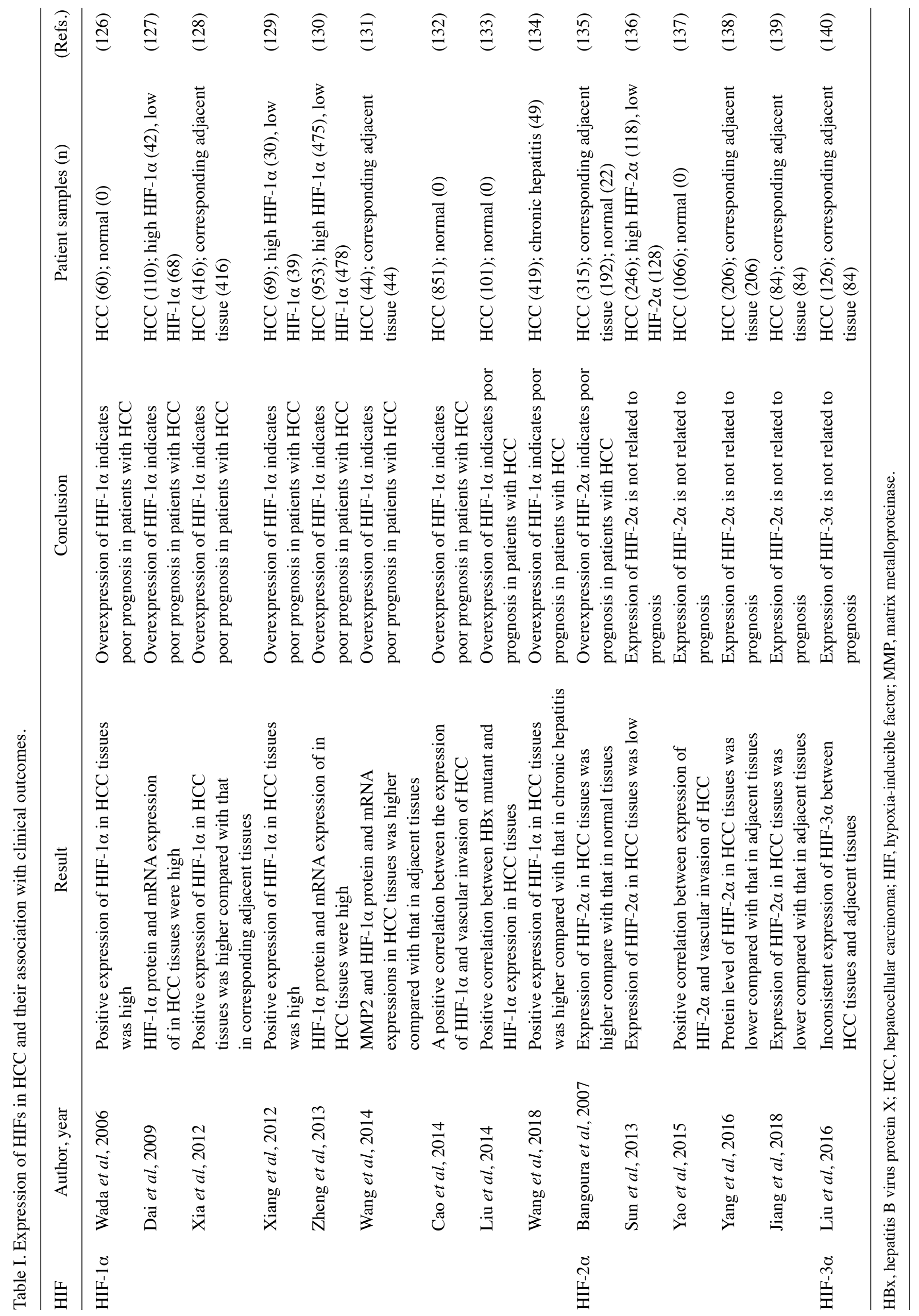




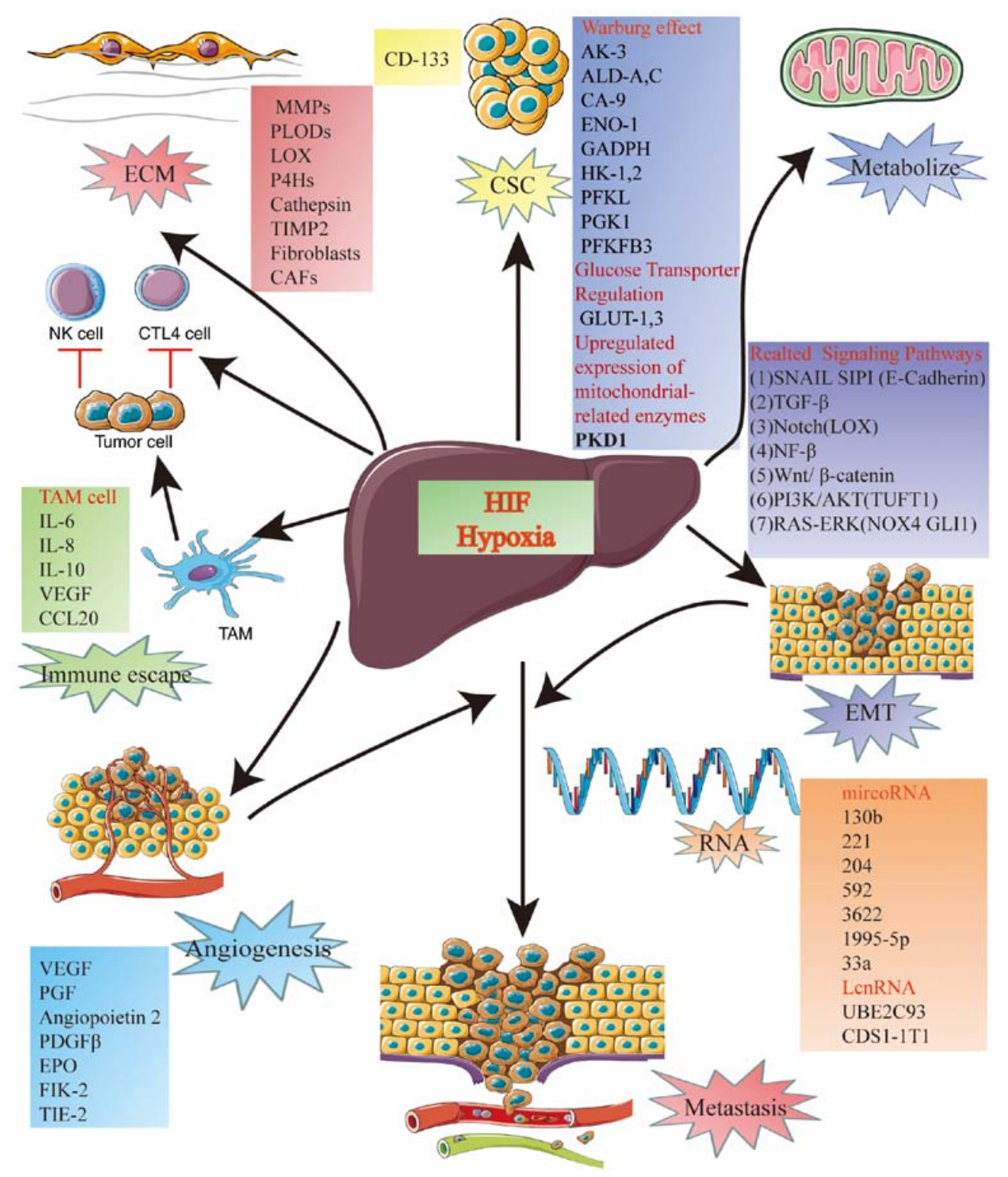

Figure 3. Relationship between HIF and HCC. The complex relationship between HIF and HCC includes metabolism, immune escape, angiogenesis, metastasis, extracellular matrix remodeling, and cancer stem cells. ALD, aldolase; AK3, adenylate kinase 3; CA9, carbonic anhydrase 9; CCL20, CAFs, cancer-related fibroblasts; C-C motif chemokine ligand 20; ECM, extracellular matrix; EMT, epithelial-mesenchymal transition; ENO1, enolase 1; EPO, erythropoietin; GLUT, glucose transporter; HK, hexokinase; LOX, lysyl oxidase; MMPs, matrix metalloproteinases; NOX4, NADPH oxidase 4; P4Hs, prolyl-4-hydroxylases; PDGF, platelet-derived growth factor; PFKFB, 3,6-phosphofructo-2-kinase/fructose-2,6-bisphosphate 3; PFKL, liver-type phosphofructokinase; PGF, placental growth factor; PGK1, phosphoglycerate kinase 1; PLODs, procollagen lysyl hydroxylases; TAM, tumor-associated macrophage; TGF- $\beta$, transforming growth factor $\beta$; TIE-2, tyrosine-protein kinase receptor TIE-2; TIMP2, tissue inhibitor of metalloproteinase 2; TUFT1, tuftelin1; VEGF, vascular endothelial growth factor.

\section{Angiogenesis}

The rapid growth of tumors necessitates the de novo formation of a large number of blood vessels to transport oxygen and nutrients. Angiogenesis is a complex process that involves the degradation of the extracellular matrix, the activation, proliferation and migration of vascular endothelial cells, and the establishment of a new vascular network (56). The most important signaling molecule in this process is VEGF (Fig. 3), which specifically promotes the proliferation and migration of vascular endothelial cells. Compared with the normal vascular system, the blood vessels of tumors are leaky, distorted and disordered. Inhibition of the expression of HIF-1 $\alpha$ in endothelial cells suppresses tumor growth, whereas inhibiting the expression of HIF-2 $\alpha$ enhances the formation of blood vessels supplying the tumor (57). However, these blood vessels are disordered and do not correct the hypoxic state of the tumor microenvironment. This phenomenon is caused by differential regulation of NO homeostasis, which in turn regulates vascular endothelial growth factor expression in the NO-dependent feedback loop (57). HIF-1 $\alpha$ is a major regulator of VEGF expression. The HIF-1 $\alpha / \mathrm{p} 300 / \mathrm{CBP}$ complex binds to the HREs in five regions of the VEGF promoter. Under hypoxia, high levels of accumulated HIF-1 $\alpha$ upregulates the expression of a series of angiogenic factors, such as VEGF, and enhances the stability of VEGF mRNA, ultimately activating tumor angiogenesis $(58,59)$. Lee et al $(60)$ used acridine flavin to inhibit the heterodimerization of HIF- $1 \alpha$ and HIF-1 $\beta$ and revealed that 
the expression of VEGF in tumor cells decreased significantly. This result provided additional evidence for the role of HIF-1 $\alpha$ in the activation of VEGF. Another study demonstrated that the levels of HIF-1 $\alpha$, as well as VEGF protein and mRNA, detected after 20 weeks of HCC were significantly higher than before 20 weeks in an experimental rat HCC model, suggesting that HIF-1 $\alpha$ and VEGF may have important functions during HCC development (61). Sorafenib, an inhibitor of multiple kinases, has been tested in clinical trials of HCC carcinoma, and the mechanism of its action has been reported to be closely related to anti-angiogenesis (62); it can effectively inhibit the expression of HIF-1 $\alpha$, thereby reducing the expression of VEGF and, ultimately, leading to a decrease in angiogenesis in tumors. In addition to VEGF, many other signaling molecules are also highly expressed under hypoxic conditions via HIF-dependent mechanisms, including angiopoietin 2 (ANG2), placental growth factor (PGF), PDGF- $\beta$ and stromal-derived factor 1 (SDF-1); all of these growth factors promote angiogenesis in tumors (63). ANG-like protein 4 (ANGL4) has also been identified as gene target of HIF-1 $\alpha$ (64); ANGL4 affects HCC angiogenesis and metastasis by modulating the expression of vascular cell adhesion molecule and integrin $\beta 1$.

In contrast to HIF- $1 \alpha$, HIF- $2 \alpha$ is only expressed during normal development of blood vessels and lungs (65). It has also been detected in tumor vascular endothelial cells, tumor cells and TAMs (66); and hypoxia-inducible expression of HIF- $2 \alpha$ has been reported in the brain, lung, heart, liver, duodenum, pancreas and kidney of mice (67). HIF-2 $\alpha$ mainly acts on angiogenesis-related genes, including VEGF, erythropoietin (EPO), VEGF receptor 2 (VEGFR2), angiogenin, and tyrosine-protein kinase receptor TIE-2 $(68,69)$; experiments using different tumor cell lines and animal models have demonstrated that HIF-2 $\alpha$ activates tumor angiogenesis by upregulating VEGF. Additionally, HIF-2 $\alpha$ forms a complex with transcription-assisted activator ETS proto-oncogene 1 (ETS-1), and binds to HRE4 on the promoter of VEGFR2, activating its expression (70).

\section{Metastasis}

Intrahepatic and extrahepatic metastasis is the major contributor to poor prognosis in patients with HCC. Invasion and metastasis of tumors is a complex process in which the first step involves EMT. In the process of EMT, polar epithelial cells transform into mobile stromal cells, gaining the ability to migrate to distant sites. HIF-1 $\alpha$ is a crucial regulator of EMT under hypoxic conditions, acting through seven distinct mechanisms detailed in the subsections below (Fig. 3).

Snail homolog 1 (SNAII) and SMAD-interacting protein 1 (SIP1) signaling pathways. Inactivation of epithelial (E)-cadherin, a protein essential for cell adhesion, results in the weakening of cell-cell contacts and increased mobility, initiating EMT. HIF-1 $\alpha$ inhibits the expression of E-cadherin by upregulating SNAI1 and SIP1, transcriptional inhibitors of E-cadherin (71). HIF-1 $\alpha$ regulates SNAI1 by binding to two HREs on the SNAI1 promoter, affecting the expression of E-cadherin, as well as $\mathrm{N}$-cadherin and vimentin, activating EMT in HCC cells and promoting HCC invasion and metastasis (72).
TGF- $\beta$ signaling pathway. The TGF- $\beta$ signaling pathway is widely involved in embryonic development, tissue and organ formation, cell proliferation, apoptosis, differentiation and migration. TGF- $\beta$ has a dual function in the development of tumors. TGF- $\beta$ signaling pathway induces EMT, facilitating the invasion and metastasis of tumors (73). It has been also demonstrated that hypoxia is an important stimulator of EMT by activating HIFs (74). Under hypoxic conditions, HIF expression in hepatocytes promotes TGF- $\beta$ signaling; HIF and TGF- $\beta$ signaling contribute to the mechanism of hypoxia-stimulated hepatocyte EMT (74). It has been reported that the TGF- $\beta 1$ pathway serves an important role in the regulation of liver cancer by regulating SMAD4, SMAD2/3, cleaved Notch1, and $\beta$-catenin proteins (75).

Notch signaling pathway. The Notch signaling pathway regulates embryonic development and differentiation, and proliferation and apoptosis of mature cells. Notch signaling induces EMT primarily by two mechanisms. The first one involves the upregulation of SNAI1 achieved by Notch-mediated recruitment of HIF-1 $\alpha$ and the resulting increase in lysyl oxidase (LOX), which stabilizes SNAI1, thus promoting EMT (76). The second mechanism relies on the interaction of Notch with the TGF- $\beta$ /SMAD pathway, which also activates EMT (77). Although the molecular mechanisms underlying hypoxia and Notch pathway activation are not clear, there is indeed a link between them. Hypoxia activates Notch-responsive promoters and increases expression of Notch direct downstream genes; the Notch intracellular domain interacts with HIF-1 $\alpha$, and after activation of Notch under hypoxic conditions, HIF-1 $\alpha$ is recruited to the Notch reactive promoter (78).

$N F-\kappa B$ signaling pathway. The presence of a bi-directional correlation between HIF and $\mathrm{NF}-\kappa \mathrm{B}$ has also been reported, in which NF- $\kappa \mathrm{B}$ can induce HIF and HIF can also regulate $\mathrm{NF}-\kappa \mathrm{B}$ (79). Cancer is characterized by the presence of hypoxia and inflammation. Hypoxia has been demonstrated to promote inflammation through the regulation of gene expression by oxygen-sensitive transcriptional regulators, including HIF and NF- $\kappa B$ (80). The basis for this association includes the regulation of the components of the $\mathrm{NF}-\kappa \mathrm{B}$ pathway and the transcriptional regulation of HIF-1 under hypoxia (81).

Wnt signaling pathway. Wnt regulates the growth, proliferation, invasion and metastasis of cancer cells. Under hypoxic conditions, an increase of Wnt3a upregulates the expression of $\beta$-catenin and promotes EMT (82). A previous study reported that the $\mathrm{Wnt} / \beta$-catenin signaling pathway enhances the transcriptional activity of HIF-1 $\alpha$ and inhibits the apoptosis of $\mathrm{HCC}$, as well as inducing EMT and triggering HCC metastasis (83). In addition, hypoxia promotes HCC cell migration and angiogenesis by regulating the expression of $\mathrm{B}$-cell CLL/lymphoma 9 (BCL9), which activates Wnt/ $\beta$-catenin signaling pathway (84).

PI3K/AKT signaling pathway. PIK3/AKT signaling is crucially involved in tumor development. Hypoxia induces the expression of tuftelin1 (TUFT1) in a HIF-1 $\alpha$-dependent manner (85). In turn, TUFT1 activates the $\mathrm{Ca}^{2+} / \mathrm{PI} 3 \mathrm{~K} / \mathrm{AKT}$ 
pathway, promoting HCC cell growth, metastasis and EMT in vitro and in vivo.

ROS signaling pathway. Hypoxia significantly promotes the progression of EMT and is associated with activation of the non-canonical Hedgehog (Hh) signaling pathway. HIF-1 $\alpha$ knockdown attenuates hypoxia-induced membrane-spanning protein SMO and glioma-associated oncogene 1 (GLI1) expression and inhibits EMT progression. In addition, SMO inhibitors or GLI1 small interfering (si)RNA can also reverse hypoxia-driven EMT under hypoxic conditions. It is suggested that non-canonical $\mathrm{Hh}$ signaling serves an important role in hypoxia-induced EMT. Hypoxia increases reactive oxygen species (ROS) production, and ROS inhibitors (NACs) block GLI1-dependent EMT processes under hypoxic conditions. In hypoxic HCC cells, nicotinamide adenine dinucleotide phosphate (NADPH) oxidase 4 (NOX4) expression was found to increase at mRNA and protein levels. siRNA-mediated knockdown of NOX4 expression abolishes hypoxia-induced ROS production and hypoxia-induced GLI1-dependent EMT. Hypoxia triggers ROS-mediated GLI1-dependent EMT progression by inducing NOX4 expression. Non-canonical Hh pathway regulates HIF-1 $\alpha / \mathrm{NOX} 4 / \mathrm{ROS}$ signaling pathway under hypoxic conditions to regulate EMT processes in HCC cells (86).

A relationship has also been identified between HIF signaling and p53 family members. A previous study reported that due to the binding of p53 protein to HIF-1 $\alpha$, p53 is stabilized, and hypoxia induction of transcriptionally active wild-type p53 gene is achieved (87). Conversely, p53 and p73 interact with HIF-1 $\alpha$, suppressing its activity, thereby inhibiting the migration and metastasis of tumor cells $(88,89)$. A number of studies have demonstrated that microRNAs (miRNAs) are also closely related to the migration and metastasis of tumors, and their effects involve the activity of HIF-1 $\alpha$. For example, miRNA (miR)-130b and miR-21 can activate EMT through the PTEN/AKT/HIF-1 $\alpha$ pathway and enhance HCC metastasis $(90,91)$. Hypoxia-induced downregulation of miR-204, which acts as a post-transcriptional regulator of vasodilator-stimulated phosphoprotein (VASP) expression, promotes intrahepatic metastasis of HCC (92). miR-199a-5p (93), miR-592 (94) and miR-3662 regulate the Warburg effect and HCC progression (95) by reducing the expression of HIF-1 $\alpha$. Hypoxia induction and up-regulation of HIF can lead to downregulation of miR-33a expression in HCC cells; miR-33a controls EMT and invasiveness of HCC by downregulating Twist1 (96). miR-26a impacts HCC angiogenesis through the PIK3C2/AKT/HIF-1 $\alpha$ /VEGFA pathway (97).

In addition to miRNAs, long non-coding RNAs (lncRNAs) can also promote HCC metastasis. The lncRNA UBE2CP3 triggers the proliferation and migration of HCC cells by activating ERK/HIF-1 $\alpha /$ p70S6K/VEGFA signal transduction (98). Previous in vitro experiments demonstrated that the lncRNA CPS1-intronic transcript 1 significantly suppresses proliferation, migration and invasion of cells by reducing the activity of Hsp90 and HIF-1 $\alpha$, thus inhibiting the EMT (99).

\section{ECM remodeling}

ECM remodeling serves a crucial role in tumor invasion and metastasis (100). Several enzymes involved in ECM deposition and remodeling are regulated by hypoxia and HIFs, including MMPs, procollagen lysyl hydroxylases (PLODs), LOXs, collagen prolyl-4-hydroxylases (P4Hs) and cathepsins (Fig. 3) (101). Hypoxia can also downregulate the expression of tissue inhibitor of metalloproteinase 2 (TIMP2) in HCC cells by a HIF1 $\alpha$-dependent mechanism (102). Fibroblasts are the most important cell type involved in ECM production and remodeling; in addition, they are one of the most abundant types of stromal cells in tumors, where they can be reprogrammed into cancer-related fibroblasts (CAFs) (103). In vitro and in vivo studies have demonstrated that the HIF- $1 \alpha / \mathrm{LOX}$ pathway is involved in ECM remodeling and promotion of HCC metastasis by a mechanism dependent on hepatitis transactivator protein $X(104)$.

\section{Cancer stem cells}

CSCs have an important function in the initiation, development, recurrence and metastasis of tumors. Studies on HIF and stem cells focused on the role of HIF in hematopoietic stem cells (105); based on data suggesting the involvement of HIF in the function of hematopoietic stem cells, studies have demonstrated that the HIF signaling pathway serve an important role in the induction and maintenance of CSC and EMT phenotypes, and regulates its function by regulating multiple complex signaling molecules within the tumor microenvironment (106). A recent study reported that hypoxia significantly enhances stem cell-related properties of HCC cells, an effect that can be abolished by the knockdown of HIF-1 $\alpha$ or HIF-2 $\alpha$ (3). Additionally, HIF-1 $\alpha$-specific small interfering RNA treatment markedly reduces the expression of CD133 in CSCs at the RNA and protein levels (107). Importantly, EMT activation can induce CSC characteristics. Notch1 mediates the process of EMT-induced CSCs by direct interaction with HIF-1 $\alpha$; upregulation of the intracellular expression of Notch by HIF-1 $\alpha$ can activate EMT and induce HCC cells to acquire the features of CSC in vitro (108).

\section{HIF-1 $\alpha$ as a therapeutic target}

Given the importance of HIF-1 $\alpha$ in promoting the initiation and development of tumors, the possibility of a therapy targeting HIFs has become a focus of intense research effort. To date, a number of drugs or compounds inhibiting HIF-1 $\alpha$ have been identified, but the drugs applicable for HCC treatment are still unsatisfactory. HIF- $1 \alpha$ inhibitors can be classified into eight categories. i) Drugs affecting the HIF-1 $\alpha$ signaling pathway. Typically, these molecules inhibit mTOR and PI3K signaling. Recombinant analgesic-antineoplastic peptide (rAGAP) is a protein comprising small ubiquitin-related modifiers linked to ubiquitin-histidine tags. rAGAP inhibits the AKT/PI3K pathway, suppressing angiogenesis and tumor progression (109). Circular RNA circ-EPHB4 derived from the gene coding for a member of the ephrin (Eph) receptor tyrosine kinase family, EphB4, prevents tumor growth by modulating the HIF-1 $\alpha$ and AKT/PI3K signaling (110). The drug salidroside significantly increases the sensitivity of HCC to platinum and inhibits hypoxia-induced EMT by blocking the HIF-1 $\alpha$ signaling (111). Rapamycin counteracts the process of EMT and angiogenesis, thus inhibiting the 
growth and lung metastasis in a rat model of HCC (112). Ruscogenin reduces the expression of MMP-2, MMP-9, urokinase plasminogen activator, VEGF and HIF-1 $\alpha$ by interfering with the PI3K/AKT/mTOR signaling pathway, resulting in an inhibition of tumor growth (113). The dietary phytochemical sulforaphane prevents angiogenesis of HCC by inhibiting STAT3/HIF-1 $\alpha /$ VEGF signal transduction (114). N1-guanyl-1,7-diaminoheptane (GC7) enhances the sensitivity of HCC to doxorubicin by reversing the EMT signaling pathway induced by HIF-1 $\alpha$ (115). Everolimus suppresses tumor growth and angiogenesis by blocking AKT/mTOR signaling pathway in vitro by promoting cell apoptosis and inhibiting endothelial cell proliferation (116). Finally, Huaier polysaccharide TP-1 is a naturally occurring bioactive macromolecule, found in Huaier fungus, prevents tumor growth and metastasis by downregulating HIF-1 $\alpha$-VEGF and AUF-1/AEG-1 signal transduction pathways (117). ii) Drugs inhibiting the expression of HIF- $1 \alpha$ mRNA. Two compounds, RO70179 and EZN-2968, have been demonstrated to markedly reduce the expression of HIF-1 $\alpha$ in HCC tissues (118). iii) Drugs inhibiting the synthesis of HIF-1 $\alpha$ protein. Topotecan, an inhibitor of topoisomerase, has been reported to block the entry of the ribosome on HIF-1 $\alpha$ mRNA, preventing translation of the protein (119). Additionally, vorinostat, a histone deacetylase inhibitor, decreases interaction between acetyl-Hsp90 and HIF-1 $\alpha$, inhibiting HIF- $\alpha$ nuclear translocation (120). iv) Drugs promoting the degradation of HIF-1 $\alpha$ protein. A previous study has reported that evodiamine in combination with vorinostat accelerated the degradation of HIF-1 $\alpha$ in HCC cells under hypoxic conditions (121). v) Drugs inhibiting HIF-1 $\alpha$ stabilization. Curcumin can induce the clearance of ROS by upregulating nuclear factor E2-related factor 2 (Nrf2) and glutathione (GSH), which inhibit the stabilization of HIF- $1 \alpha$, and, in turn, suppress the expression of connective tissue growth factor (CTGF), providing a protective effect on HCC (122). vi) Drugs blocking the binding of HIF-1 $\alpha$ to target genes; for example, doxorubicin (115). vii) Drugs inhibiting HIF-1 $\alpha$-mediated transcriptional activation; for example, bortezomib (123). viii) Drugs used for systemic therapy. A previous study demonstrated that inhibition of HIF-1 $\alpha$ by systemic therapy with digoxin significantly delayed the development of HCC (124). In addition, metformin was reported to enhance the potential of regorafenib by regulating the levels of HIV TAT-interactive protein (TIP30) and HIF- $2 \alpha$, and inhibits the recurrence and metastasis of HCC after hepatectomy (125).

\section{Conclusions and future perspectives}

The expression of HIF-1 $\alpha$ in HCC is significantly higher compared with expression in normal liver cells. HIF-1 $\alpha$ is a crucial regulator of the adaptation of HCC cells to the hypoxic microenvironment and can affect the proliferation, growth, invasion, metastasis, angiogenesis, apoptosis and drug resistance of HCC cells by modulating the expression of multiple target genes. A number of studied have demonstrated the feasibility of using HIF-1 $\alpha$ as a therapeutic target, which suggested that interventions modifying the activity of HIF- $1 \alpha$ by direct or indirect ways may become effective for the treatment of HCC. Despite the growing number of studies on HIF-1 $\alpha$ and identification of many HIF-1 $\alpha$ inhibitors, their therapeutic application has not moved beyond the pre-clinical stage. Clinical use of these inhibitors faces multiple problems which have to be solved urgently. They include limitations in the specificity of HIF-1 $\alpha$ inhibitors and lack of definitive cytotoxicity of HIF-1 $\alpha$ inhibitors toward cancer cells. Therefore, compounds need to be developed and screened for clinical application. In the case of YC-1 and other similarly well-investigated inhibitors, further research on their pharmacology and toxicology is still needed. Although gene therapy targeting HIF-1 $\alpha$ brings new hope to the treatment of HCC, finding the target gene is only the first step in the long road to clinical application. How to construct a safe and efficient vector, how to search for specific transcriptional regulatory elements in HCC, and how to rationally apply a combined therapy targeting multiple genes are critical questions that must be conclusively answered. Therefore, studies on the function of HIF-1 in HCC have to be expanded, necessitating additional time before the targeted therapy of HIF-1 $\alpha$ for HCC can be implemented clinically. In addition, the understanding of the function of HIF-2 and HIF-3 in HCC has only begun to emerge, although it is already documented that HIF- $2 \alpha$ affects HCC energy metabolism, angiogenesis, cell proliferation and tumor growth. Other studies have provided information regarding the stability, transcriptional activity and role of HIF- $2 \alpha$ in HCC growth and progression, but the exact role in HCC remains unclear. It is generally believed that HIF-2 $\alpha$ can be activated in most hypoxic solid tumors, but whether its activation promotes or inhibits tumor growth depends on the biological environment of the tumor. HIF- $2 \alpha$ can participate in modulating the progression of HCC through different signaling pathways. However, the specific role of HIF- $2 \alpha$ in HCC is still controversial, and definite conclusions have can only be provided by additional experiments. Thus, in-depth analysis of the function of HIF- $2 \alpha$ in HCC may help to better understand the mechanism of development and metastasis of this tumor type and to improve the treatment methods. In conclusion, significant additional research effort is necessary to achieve an in-depth understanding of the role of HIFs in HCC.

\section{Acknowledgements}

Not applicable.

\section{Funding}

This study was supported by The Key Laboratory of Tumor Molecular Diagnosis and Individualized Medicine of Zhejiang Province, Zhejiang Provincial People's Hospital (People's Hospital of Hangzhou Medical College; Hangzhou, China). This study was also supported by grants from The National Science and Technology Major Project for New Drug (grant no. 2017ZX09302003), The National Natural Science Foundation of China (grant nos. 81874049 and 81602179), The Co-construction of Provincial and Department Project (grant no. WKJ-ZJ-1919), The Zhejiang Provincial Natural Science Foundation of China (grant no. LY19H160036), and The Public Projects of Zhejiang Province (grant no. 2018C37033). 


\section{Availability of data and materials}

Not applicable.

\section{Authors' contributions}

YG, ZX, DH and QX conceived and designed the review. YG, ZX, LY, YG, QZ, LH, DH and QX were involved in the collection and collation of references. YG and ZX collected and assembled the data presented in Table I. YG and ZX drew the figures. YG and ZX wrote the manuscript. All authors approved the final manuscript.

\section{Ethics approval and consent to participate}

Not applicable.

\section{Patient consent for publication}

Not applicable.

\section{Competing interests}

The authors declare that they have no competing interests.

\section{References}

1. Chen W, Zheng R, Baade PD, Zhang S, Zeng H, Bray F, Jemal A, Yu XQ and He J: Cancer statistics in China, 2015. Ca Cancer J Clin 66: 115-132, 2016.

2. Mckeown SR: Defining normoxia, physoxia and hypoxia in tumours-implications for treatment response. Br J Radiol 87: 20130676, 2014.

3. Cui CP, Wong CC, Kai AK, Ho DW, Lau EY, Tsui YM, Chan LK, Cheung TT, Chok KS, Chan ACY, et al: SENP1 promotes hypoxia-induced cancer stemness by HIF-1 $\alpha$ deSUMOylation and SENP1/HIF-1 $\alpha$ positive feedback loop. Gut 66: 2149-2159, 2017.

4. Wang J, Ma Y, Jiang H, Zhu H, Liu L, Sun B, Pan S, Krissansen GW and Sun X: Overexpression of von Hippel-Lindau protein synergizes with doxorubicin to suppress hepatocellular carcinoma in mice. J Hepatol 55: 359-368, 2011.

5. Blagosklonny MV: Hypoxia-inducible factor: Achilles' heel of antiangiogenic cancer therapy (Review). Int J Oncol 19: 257-262, 2001.

6. Dengler VL, Galbraith MD and Espinosa JM: Transcriptional regulation by hypoxia inducible factors. Crit Rev Biochem Mol Biol 49: 1-15, 2014.

7. Hu CJ, Sataur A, Wang L, Chen $\mathrm{H}$ and Simon MC: The $\mathrm{N}$-terminal Transactivation domain confers target gene specificity of hypoxia-inducible factors HIF-1alpha and HIF-2alpha. Mol Biol Cell 18: 4528-4542, 2007.

8. Ohh M, Park CW, Ivan M, Hoffman MA, Kim TY, Huang LE, Pavletich N, Chau V and Kaelin WG: Ubiquitination of hypoxia-inducible factor requires direct binding to the beta-domain of the von Hippel-Lindau protein. Nat Cell Biol 2: 423-427, 2000.

9. Maxwell PH, Wiesener MS, Chang GW, Clifford SC, Vaux EC, Cockman ME, Wykoff CC, Pugh CW, Maher ER and Ratcliffe PJ: The tumour suppressor protein VHL targets hypoxia-inducible factors for oxygen-dependent proteolysis. Nature 399: 271-275, 1999.

10. Ivan M, Kondo K, Yang H, Kim W, Valiando J, Ohh M, Salic A Asara JM, Lane WS and Kaelin WG Jr: HIFalpha targeted for VHL-mediated destruction by proline hydroxylation: Implications for O2 sensing. Science 292: 464-468, 2001.

11. Garvalov BK and Acker T: Implications of oxygen homeostasis for tumor biology and treatment 903: 169-185, 2016.

12. Benita Y, Kikuchi H, Smith AD, Zhang MQ, Chung DC and Xavier RJ: An integrative genomics approach identifies Hypoxia Inducible Factor-1 (HIF-1)-target genes that form the core response to hypoxia. Nucleic Acids Res 37: 4587-4602, 2009.
13. Salminen A, Kauppinen A and Kaarniranta K: 2-Oxoglutaratedependent dioxygenases are sensors of energy metabolism, oxygen availability, and iron homeostasis: Potential role in the regulation of aging process. Cell Mol Life Sci 72: 3897-3914, 2015.

14. Briggs KJ, Koivunen P, Cao S, Backus KM, Olenchock BA, Patel H, Zhang Q, Signoretti S, Gerfen GJ, Richardson AL, et al: Paracrine Induction of HIF by glutamate in breast cancer: EglN1 senses cysteine. Cell 166: 126-139, 2016.

15. Lau CK, Yang ZF, Ho DW, Ng MN, Yeoh GC, Poon RT and Fan ST: An AKT/hypoxia-inducible factor-1alpha/platelet-derived growth factor-BB autocrine loop mediates hypoxia-induced chemoresistance in liver cancer cells and tumorigenic hepatic progenitor cells. Clin Cancer Res 15: 3462-3471, 2009.

16. Akeno N, Robins J, Zhang M, Czyzyk-Krzeska MF and Clemens TL: Induction of vascular endothelial growth factor by IGF-I in osteoblast-like cells is mediated by the PI3K signaling pathway through the hypoxia-inducible factor-2alpha. Endocrinology 143: 420-425, 2002.

17. Fukuda R, Hirota K, Fan F, Jung YD, Ellis LM and Semenza GL: Insulin-like growth factor 1 induces hypoxia-inducible factor 1-mediated vascular endothelial growth factor expression, which is dependent on MAP kinase and phosphatidylinositol 3-kinase signaling in colon cancer cells. J Biol Chem 277: 38205-38211, 2002.

18. Biswas S, Mukherjee R, Tapryal N, Singh AK and Mukhopadhyay CK: Insulin regulates hypoxia-inducible factor-1 $\alpha$ transcription by reactive oxygen species sensitive activation of Sp1 in 3T3-L1 preadipocyte. PLoS One 8: e62128, 2013.

19. Laughner E, Taghavi P, Chiles K, Mahon PC and Semenza GL: HER2 (neu) signaling increases the rate of hypoxia-inducible factor 1alpha (HIF-lalpha) synthesis: Novel mechanism for HIF-1-mediated vascular endothelial growth factor expression. Mol Cell Biol 21: 3995-4004, 2001.

20. Nayak BK, Feliers D, Sudarshan S, Friedrichs WE, Day RT, New DD, Fitzgerald JP, Eid A, Denapoli T, Parekh DJ, et al: Stabilization of HIF-2 $\alpha$ through redox regulation of $m$ TORC2 activation and initiation of mRNA translation. Oncogene 32: 3147-3155, 2013

21. Liu LZ, Hu XW, Xia C, He J, Zhou Q, Shi X, Fang J and Jiang BH: Reactive oxygen species regulate epidermal growth factor-induced vascular endothelial growth factor and hypoxia-inducible factor-1alpha expression through activation of AKT and P70S6K1 in human ovarian cancer cells. Free Radic Biol Med 41: 1521-1533, 2006.

22. Jiang BH, Jiang G, Zheng JZ, Lu Z, Hunter T and Vogt PK: Phosphatidylinositol 3-kinase signaling controls levels of hypoxia-inducible factor 1. Cell Growth Differ 12: 363-369, 2001.

23. Lim JH, Lee YM, Chun YS, Chen J, Kim JE and Park JW: Sirtuin 1 modulates cellular responses to hypoxia by deacetylating hypoxia-inducible factor lalpha. Mol Cell 38: 864-878, 2010.

24. Liu X, Chen S, Tu J, Cai W and Xu Q: HSP90 inhibits apoptosis and promotes growth by regulating HIF-1 $\alpha$ abundance in hepatocellular carcinoma. Int J Mol Med 37: 825-835, 2016.

25. van Hagen M, Overmeer RM, Abolvardi SS and Vertegaal AC: RNF4 and VHL regulate the proteasomal degradation of SUMO-conjugated Hypoxia-Inducible Factor-2alpha. Nucleic Acids Res 38: 1922-1931, 2010.

26. Duan C: Hypoxia-inducible factor 3 biology: Complexities and emerging themes. Am J Physiol Cell Physiol 310: C260-C269, 2016.

27. Makino Y, Kanopka A, Wilson WJ, Tanaka H and Poellinger L: Inhibitory PAS domain protein (IPAS) is a hypoxia-inducible splicing variant of the hypoxia-inducible factor-3alpha locus. J Biol Chem 277: 32405-32408, 2002.

28. Maynard MA, Qi H, Chung J, Lee EH, Kondo Y, Hara S, Conaway RC, Conaway JW and Ohh M: Multiple splice variants of the human HIF-3 alpha locus are targets of the von Hippel-Lindau E3 ubiquitin ligase complex. J Biol Chem 278: 11032-11040, 2003.

29. Heikkilä M, Pasanen A, Kivirikko KI and Myllyharju J: Roles of the human hypoxia-inducible factor (HIF)-3 $\alpha$ variants in the hypoxia response. Cell Mol Life Sci 68: 3885-3901, 2011.

30. Chen $C$ and Lou T: Hypoxia inducible factors in hepatocellular carcinoma. Oncotarget 8: 46691-46703, 2017.

31. Mucaj V, Shay JE and Simon MC: Effects of hypoxia and HIFs on cancer metabolism. Int J Hematol 95: 464-470, 2012.

32. Warburg O, Wind $\mathrm{F}$ and Negelein E: The metabolism of tumors in the body. J Gen Physiol 8: 519-530, 1927. 
33. Alfarouk KO, Verduzco D, Rauch C, Muddathir AK, Adil HH, Elhassan GO, Ibrahim ME, David Polo Orozco J, Cardone RA, Reshkin SJ and Harguindey S: Glycolysis, tumor metabolism, cancer growth and dissemination. A new $\mathrm{pH}$-based etiopathogenic perspective and therapeutic approach to an old cancer question. Oncoscience 1: 777-802, 2014.

34. Liberti MV and Locasale JW: The warburg effect: How does it benefit cancer cells? Trends Biochem Sci 41: 211-218, 2016

35. Denko NC: Hypoxia, HIF1 and glucose metabolism in the solid tumour. Nat Rev Cancer 8: 705-713, 2008.

36. Semenza GL: Regulation of cancer cell metabolism by hypoxia-inducible factor 1. Semin Cancer Biol 19: 12-16, 2009.

37. Semenza GL: HIF-1: Upstream and downstream of cancer metabolism. Curr Opin Genet Dev 20: 51-56, 2010.

38. Ke Q and Costa M: Hypoxia-Inducible Factor-1 (HIF-1). Mol Pharmacol 70: 1469-1480, 2006.

39. Marín-Hernández A, Gallardo-Pérez JC, Ralph SJ, Rodríguez-Enríquez S and Moreno-Sánchez R: HIF-1alpha modulates energy metabolism in cancer cells by inducing over-expression of specific glycolytic isoforms. Mini Rev Med Chem 9: 1084-1091, 2009.

40. Kim JW, Tchernyshyov I, Semenza GL and Dang CV: HIF-1-mediated expression of pyruvate dehydrogenase kinase: A metabolic switch required for cellular adaptation to hypoxia. Cell Metab 3: 177-185, 2006.

41. Weidemann A and Johnson RS: Biology of HIF-1 alpha. Cell Death Differ 15: 621-627, 2008.

42. Graziano F, Ruzzo A, Giacomini E, Ricciardi T, Aprile G, Loupakis F, Lorenzini P, Ongaro E, Zoratto F, Catalano V, et al: Glycolysis gene expression analysis and selective metabolic advantage in the clinical progression of colorectal cancer. Pharmacogenomics J 17: 258-264, 2017.

43. Schito L and Semenza GL: Hypoxia-inducible factors: Master regulators of cancer progression. Trends Cancer 2: 758-770, 2016

44. Samanta D, Park Y, Ni X, Li H, Zahnow CA, Gabrielson E, Pan F and Semenza GL: Chemotherapy induces enrichment of $\mathrm{CD} 47^{+} / \mathrm{CD}^{2} 3^{+} / \mathrm{PDL}^{+}$immune evasive triple-negative breast cancer cells. Proc Natl Acad Sci USA 115: E1239-E1248, 2018.

45. Terry S, Buart S and Chouaib S: Hypoxic stress-induced tumor and immune plasticity, suppression, and impact on tumor heterogeneity. Front Immunol 8: 1625, 2017.

46. Noman MZ, Janji B, Kaminska B, Moer KV, Pierson S, Przanowski P, Buart S, Berchem G, Romero P, Mami-Chouaib F and Chouaib S: Blocking hypoxia-induced autophagy in tumors restores cytotoxic t-cell activity and promotes regression. Autophagy 71: 5976-5986, 2012.

47. Hatfield SM and Sitkovsky M: A2A adenosine receptor antagonists to weaken the hypoxia-HIF-1 $\alpha$ driven immunosuppression and improve immunotherapies of cancer. Curr Opin Pharmacol 29: 90-96, 2016.

48. Vinit $\mathrm{K}$ and Gabrilovich DI: Hypoxia-inducible factors in regulation of immune responses in tumour microenvironment. Immunology 143: 512-519, 2014

49. Fukuda K, Kobayashi A and Watabe K: The role of tumorassociated macrophage in tumor progression. Front Biosci 4 787-798, 2012

50. Zhu XD, Zhang JB, Zhuang PY, Zhu HG, Zhang W, Xiong YQ, Wu WZ, Wang L, Tang ZY and Sun HC: High expression of macrophage colony-stimulating factor in peritumoral liver tissue is associated with poor survival after curative resection of hepatocellular carcinoma. J Clin Oncol 26: 2707-2716, 2008.

51. Wu Q, Zhou W, Yin S, Zhou Y, Chen T, Qian J, Su R, Hong L, $\mathrm{Lu} \mathrm{H}$, Zhang F, et al: Blocking TREM-1 Tumor-associated macrophages induced by hypoxia reverses immunosuppression and anti-PD-L1 resistance in liver cancer. Hepatology 70 : 198-214, 2019.

52. Zeisberger SM, Odermatt B, Marty C, Zehnder-Fjällman AH, Ballmer-Hofer K and Schwendener RA: Clodronate-liposomemediated depletion of tumour-associated macrophages: A new and highly effective antiangiogenic therapy approach. Br J Cancer 95: 272-281, 2006.

53. Kuang DM, Peng C, Zhao Q, Wu Y, Chen MS and Zheng L: Activated monocytes in peritumoral stroma of hepatocellular carcinoma promote expansion of memory $\mathrm{T}$ helper 17 cells. Hepatology 51: 154-164, 2010.

54. Jiang J, Wang GZ, Wang Y, Huang HZ, Li WT and Qu XD: Hypoxia-induced HMGB1 expression of HCC promotes tumor invasiveness and metastasis via regulating macrophage-derived IL-6. Exp Cell Res 367: 81-88, 2018.
55. Ye LY, Chen W, Bai XL, Xu XY, Zhang Q, Xia XF, Sun X, Li GG, Hu QD, Fu QH and Liang TB: Hypoxia-induced epithelial-to-mesenchymal transition in hepatocellular carcinoma induces an immunosuppressive tumor microenvironment to promote metastasis. Cancer Res 76: 818-830, 2016.

56. Payne SJ and Louise J: Influence of the tumor microenvironment on angiogenesis. Future Oncol 7: 395-408, 2011.

57. Branco-Price C, Zhang N, Schnelle M, Evans C, Katschinski DM, Liao D, Ellies L and Johnson RS: Endothelial cell HIF-1a and HIF-2 $\alpha$ differentially regulate metastatic success. Cancer Cell 21: 52-65, 2012.

58. De Francesco EM, Lappano R, Santolla MF, Marsico S, Caruso A and Maggiolini M: HIF-1 $\alpha /$ GPER signaling mediates the expression of VEGF induced by hypoxia in breast cancer associated fibroblasts (CAFs). Breast Cancer Res 15: R64, 2013.

59. Ahluwalia A and Tarnawski AS: Critical role of hypoxia sensor-HIF-1 $\alpha$ in VEGF gene activation. Implications for angiogenesis and tissue injury healing. Curr Med Chem 19: 90-97, 2012.

60. Lee K, Zhang H, Qian DZ, Rey S, Liu JO and Semenza GL: Acriflavine inhibits HIF-1 dimerization, tumor growth, and vascularization. Proc Natl Acad Sci USA 106: 17910-17915, 2009.

61. Wang W, Xu GL, Jia WD, Wang ZH, Li JS, Ma JL, Ge YS, Xie SX and $\mathrm{Yu} \mathrm{JH}$ : Expression and correlation of hypoxia-inducible factor-1alpha, vascular endothelial growth factor and microvessel density in experimental rat hepatocarcinogenesis. J Int Med Res 37: 417-425, 2009.

62. Liu LP, Ho RL, Chen GG and Lai PB: Sorafenib inhibits hypoxia-inducible factor- $1 \alpha$ synthesis: Implications for antiangiogenic activity in hepatocellular carcinoma. Clin Cancer Res 18: 5662-5671, 2012.

63. Semenza GL: Defining the role of hypoxia-inducible factor 1 in cancer biology and therapeutics. Oncogene 29: 625-634, 2010.

64. Li H, Ge C, Zhao F, Yan M, Hu C, Jia D, Tian H, Zhu M, Chen T, Jiang G, et al: Hypoxia-inducible factor 1 alpha-activated angiopoietin-like protein 4 contributes to tumor metastasis via vascular cell adhesion molecule-1/integrin $\beta 1$ signaling in human hepatocellular carcinoma. Hepatology 54: 910-919, 2011.

65. Tian H, McKnight SL and Russell DW: Endothelial PAS domain protein 1 (EPAS1), a transcription factor selectively expressed in endothelial cells. Genes Dev 11: 72-82, 1997.

66. Talks KL, Turley H, Gatter KC, Maxwell PH, Pugh CW, Ratcliffe PJ and Harris AL: The expression and distribution of the hypoxia-inducible factors HIF-1alpha and HIF-2alpha in normal human tissues, cancers, and tumor-associated macrophages. Am J Pathol 157: 411-421, 2000.

67. Wiesener MS, Jürgensen JS, Rosenberger C, Scholze CK, Hörstrup JH, Warnecke C, Mandriota S, Bechmann I, Frei UA, Pugh CW, et al: Widespread hypoxia-inducible expression of HIF-2alpha in distinct cell populations of different organs. FASEB J 17: 271-273, 2003.

68. Zhang T, Niu X, Liao L, Cho EA and Yang H: The Contributions of HIF-Target Genes to Tumor Growth in RCC. PLoS One 8: e80544, 2013

69. Feng N, Chen H, Fu S, Bian Z, Lin X, Yang L, Gao Y, Fang J and Ge Z: HIF-1 $\alpha$ and HIF- $\alpha$ induced angiogenesis in gastrointestinal vascular malformation and reversed by thalidomide. Sci Rep 6: 27280, 2016

70. Aprelikova O, Wood M, Tackett S, Chandramouli GV and Barrett JC: Role of ETS transcription factors in the hypoxia-inducible factor-2 target gene selection. Cancer Res 66: 5641-5647, 2006.

71. Evans AJ, Russell RC, Roche O, Burry TN, Fish JE, Chow VW, Kim WY, Saravanan A, Maynard MA, Gervais ML, et al: VHL promotes E2 box-dependent E-cadherin transcription by HIF-mediated regulation of SIP1 and snail. Mol Cell Biol 27: 157-169, 2007.

72. Zhang L, Huang G, Li X, Zhang Y, Jiang Y, Shen J, Liu J, Wang Q, Zhu J, Feng X, et al: Hypoxia induces epithelial-mesenchymal transition via activation of SNAI1 by hypoxia-inducible factor-1 $\alpha$ in hepatocellular carcinoma. Bmc Cancer 13: 108, 2013.

73. Willis BC, Liebler JM, Luby-Phelps K, Nicholson AG, Crandall ED, du Bois RM and Borok Z: Induction of epithelial-mesenchymal transition in alveolar epithelial cells by transforming growth factor-beta1: Potential role in idiopathic pulmonary fibrosis. Am J Pathol 166: 1321-1332, 2005.

74. Copple BL: Hypoxia stimulates hepatocyte epithelial to mesenchymal transition by hypoxia-inducible factor and transforming growth factor-beta-dependent mechanisms. Liver Int 30: 669-682, 2010 
75. Wang XH, Liu MN, Sun X, Xu CH, Liu J, Chen J, Xu RL and Li BX: TGF- $\beta 1$ pathway affects the protein expression of many signaling pathways, markers of liver cancer stem cells, cytokeratins, and TERT in liver cancer HepG2 cells. Tumor Biol 37: 3675-3681, 2016.

76. Erler JT and Giaccia AJ: Lysyl oxidase mediates hypoxic control of metastasis. Cancer Res 66: 10238-10241, 2006.

77. Sahlgren C, Gustafsson MV, Jin S, Poellinger L and Lendahl U: Notch signaling mediates hypoxia-induced tumor cell migration and invasion. Proc Natl Acad Sci USA 105: 6392-6397, 2008.

78. Gustafsson MV,Zheng X, Pereira T, Gradin K, Jin S, Lundkvist J, Ruas JL, Poellinger L, Lendahl U and Bondesson M: Hypoxia requires notch signaling to maintain the undifferentiated cell state. Dev Cell 9: 617-628, 2005.

79. D'Ignazio L, Batie M and Rocha S: Hypoxia and inflammation in cancer, focus on HIF and NF-кB. Biomedicines 5: E21, 2017.

80. Fitzpatrick SF, Tambuwala MM, Bruning U, Schaible B, Scholz CC, Byrne A, O'Connor A, Gallagher WM, Lenihan CR, Garvey JF, et al: An intact canonical NF- $\mathrm{B}$ pathway is required for inflammatory gene expression in response to hypoxia. J Immunol 186: 1091-1096, 2011.

81. Taylor CT and Cummins EP: The role of NF-kappaB in hypoxia-induced gene expression. Ann N Y Acad Sci 1177: $178-184,2010$

82.Zhang L, Liu H, Mu X, Cui J and Peng Z: Dysregulation of Fra1 expression by $\mathrm{Wnt} / \beta$-catenin signalling promotes glioma aggressiveness through epithelial-mesenchymal transition. Biosci Rep 37: BSR20160643, 2017.

83. Zhang Q, Bai X, Chen W, Ma T, Hu Q, Liang C, Xie S, Chen $\mathrm{C}, \mathrm{Hu} \mathrm{L}, \mathrm{Xu} \mathrm{S}$ and Liang T: Wnt//-catenin signaling enhances hypoxia-induced epithelial-mesenchymal transition in hepatocellular carcinoma via crosstalk with hif-1 $\alpha$ signaling. Carcinogenesis 34: 962-973, 2013.

84. Xu W, Zhou W, Cheng M, Wang J, Liu Z, He S, Luo X, Huang W, Chen T, Yan W and Xiao J: Hypoxia activates Wnt/ $\beta$-catenin signaling by regulating the expression of BCL9 in human hepatocellular carcinoma. Sci Rep 7: 40446, 2017.

85. Dou C, Zhou Z, Xu Q, Liu Z, Zeng Y, Wang Y, Li Q, Wang L, Yang W, Liu Q and Tu K: Hypoxia-induced TUFT1 promotes the growth and metastasis of hepatocellular carcinoma by activating the $\mathrm{Ca}^{2+} / \mathrm{PI} 3 \mathrm{~K} / \mathrm{AKT}$ pathway. Oncogene 38: 1239-1255, 2019.

86. Liu Z, Tu K, Wang Y, Yao B, Li Q, Wang L, Dou C, Liu Q and Zheng X: Hypoxia accelerates aggressiveness of hepatocellular carcinoma cells involving oxidative stress, epithelial-mesenchymal transition and non-canonical hedgehog signaling. Cell Physiol Biochem 44: 1856-1868, 2017.

87. An WG, Kanekal M, Simon MC, Maltepe E, Blagosklonny MV and Neckers LM: Stabilization of wild-type p53 by hypoxia-inducible factor 1alpha. Nature 392: 405-408, 1998

88. Hansson LO, Friedler A, Freund S, Rüdiger S and Fersht AR: Two sequence motifs from HIF-1alpha bind to the DNA-binding site of p53. Proc Natl Acad Sci USA 99: 10305-10309, 2002.

89. Amelio I, Inoue S, Markert EK, Levine AJ, Knight RA, Mak TW and Melino G: TAp73 opposes tumor angiogenesis by promoting hypoxia-inducible factor $1 \alpha$ degradation. Proc Natl Acad Sci USA 112: 226-231, 2015.

90. Liu Z, Wang J, Guo C and Fan X: microRNA-21 mediates epithelial-mesenchymal transition of human hepatocytes via PTEN/AKT pathway. Biomed Pharmacother 69: 24-28, 2015.

91. Chang RM, Xu JF, Fang F, Yang Hand Yang LY: MicroRNA-130b promotes proliferation and EMT-induced metastasis via PTEN/p-AKT/HIF-1 $\alpha$ signaling. Tumor Biol 37: 10609-10619, 2016

92.Liu Z, Wang Y, Dou C, Xu M, Sun L, Wang L, Yao B, Li Q, Yang W, Tu K and Liu Q: Hypoxia-induced up-regulation of VASP promotes invasiveness and metastasis of hepatocellular carcinoma. Theranostics 8: 4649-4663, 2018.

93. Li B, He L, Zuo D, He W, Wang Y, Zhang Y, Liu W and Yuan Y Mutual Regulation of MiR-199a-5p and HIF-1 $\alpha$ modulates the warburg effect in hepatocellular carcinoma. J Cancer 8 : 940-949, 2017

94. Jia YY, Zhao JY, Li BL, Gao K, Song Y, Liu MY, Yang XJ, Xue Y, Wen AD and Shi L: miR-592/WSB1/HIF-1 $\alpha$ axis inhibits glycolytic metabolism to decrease hepatocellular carcinoma growth. Oncotarget 7: 35257-35269, 2016.

95. Chen Z, Zuo X, Zhang Y, Han G, Zhang L, Wu J and Wang X: MiR-3662 suppresses hepatocellular carcinoma growth through inhibition of HIF-1 $\alpha$-mediated Warburg effect. Cell Death Dis 9: 549, 2018.
96. Guo XF, Wang AY and Liu J: HIFs-MiR-33a-Twsit1 axis can regulate invasiveness of hepatocellular cancer cells. Eur Rev Med Pharmacol Sci 20: 3011-3016, 2016.

97. Chai ZT, Kong J, Zhu XD, Zhang YY, Lu L, Zhou JM, Wang LR, Zhang KZ, Zhang QB, Ao JY, et al: MicroRNA-26a inhibits angiogenesis by down-regulating VEGFA through the PIK3C $2 \alpha / \mathrm{AKT} / \mathrm{HIF}-1 \alpha$ pathway in hepatocellular carcinoma. PLoS One 8: e77957, 2013.

98. Lin J, Cao S, Wang Y, Hu Y, Liu H, Li J, Chen J, Li P, Liu J, Wang $Q$ and Zheng L: Long non-coding RNA UBE2CP3 enhances HCC cell secretion of VEGFA and promotes angiogenesis by activating ERK1/2/HIF-1 $\alpha$ /VEGFA signalling in hepatocellular carcinoma. J Exp Clin Cancer Res 37: 113, 2018.

99. Wang TH, Yu CC, Lin YS, Chen TC, Yeh CT, Liang KH, Shieh TM, Chen CY and Hsueh C: Long noncoding RNA CPS1-IT1 suppresses the metastasis of hepatocellular carcinoma by regulating HIF- $1 \alpha$ activity and inhibiting epithelial-mesenchymal transition. Oncotarget 7: 43588-43603, 2016.

100. Bonnans C, Chou J and Werb Z: Remodelling the extracellular matrix in development and disease. Nat Rev Mol Cell Biol 15: 786-801, 2014

101. Rankin EB and Giaccia AJ: Hypoxic control of metastasis. Science 352: 175-180, 2016.

102. Kai AK, Chan LK, Lo RC, Lee JM, Wong CC, Wong JC and $\mathrm{Ng}$ IO: Down-regulation of TIMP 2 by HIF- $1 \alpha / \mathrm{miR}-210 / \mathrm{HIF}-3 \alpha$ regulatory feedback circuit enhances cancer metastasis in hepatocellular carcinoma. Hepatology 64: 473-487, 2016.

103. Kalluri R: The biology and function of fibroblasts in cancer. Nat Rev Cancer 16: 582-598, 2016.

104. Tse AP, Sze KM, Shea QT, Chiu EY, Tsang FH, Chiu DK, Zhang MS, Lee D, Xu IM, Chan CY, et al: Hepatitis transactivator protein $\mathrm{X}$ promotes extracellular matrix modification through HIF/LOX pathway in liver cancer. Oncogenesis 7: 44, 2018.

105. Cheng ZC and Sadek HA: Hypoxia and metabolic properties of hematopoietic stem cells. Antioxid Redox Signal 20: 1891-1901, 2014.

106. Bao B, Azmi AS, Ali S, Ahmad A, Li Y, Banerjee S, Kong D and Sarkar FH: The biological kinship of hypoxia with CSC and EMT and their relationship with deregulated expression of miRNAs and tumor aggressiveness. Biochim Biophys Acta 1826: 272-296, 2012.

107. Lai FB, Liu WT, Jing YY, Yu GF, Han ZP, Yang X, Zeng JX, Zhang HJ, Shi RY, Li XY, et al: Lipopolysaccharide supports maintaining the stemness of CD133(+) hepatoma cells through activation of the NF-кB/HIF-1 $\alpha$ pathway. Cancer Lett 378: 131-141, 2016

108. Jing L, Ruan Z, Sun H, Li Q, Han L, Huang L, Yu S, Wang Y, Guo $\mathrm{H}$ and Jiao M: Epithelial-mesenchymal transition induced cancer-stem-cell-like characteristics in hepatocellular carcinoma. J Cell Physiol 234: 18448-18458, 2019.

109. Cao Q, Lu W, Zhou T, Liu Y, Cai X, Zhu J and Cao P. Analgesic-antitumor peptide inhibits angiogenesis by suppressing AKT activation in hepatocellular carcinoma. Mol Cell Biochem 455: 119-125, 2019.

110. Tan Y, Du B, Zhan Y, Wang K, Wang X, Chen B, Wei X and Xiao J: Antitumor effects of circ-EPHB4 in hepatocellular carcinoma via inhibition of HIF-1 $\alpha$. Mol Carcinog 58: 875-886, 2019.

111. Qin Y, Liu HJ, Li M, Zhai DH, Tang YH, Yang L, Qiao KL, Yang JH, Zhong WL, Zhang Q, et al: Salidroside improves the hypoxic tumor microenvironment and reverses the drug resistance of platinum drugs via HIF- $1 \alpha$ signaling pathway. EBioMedicine 38: 25-36, 2018.

112. Lei HW, Cai J, Li CM, Yang F, Shi WQ, Shi WQ, Wang LP and Feng YY: Rapamycin combi with TAE on the growth, metastasis, and prognosis of hepatocellular carcinoma in rat models. Ann Hepatol 17: 645-654, 2018.

113. Hua H, Zhu Y and Song YH: Ruscogenin suppressed the hepatocellular carcinoma metastasis via PI3K/AKT/mTOR signaling pathway. Biomed Pharmacother 101: 115-122, 2018.

114. Liu P, Atkinson SJ, Akbareian SE, Zhou Z, Munsterberg A Robinson SD and Bao Y: Sulforaphane exerts anti-angiogenesis effects against hepatocellular carcinoma through inhibition of STAT3/HIF-1 $\alpha$ /VEGF signalling. Sci Rep 7: 12651, 2017.

115. Zhou QY, Tu CY, Shao CX, Wang WK, Zhu JD, Cai Y, Mao JY and Chen W: GC7 blocks epithelial-mesenchymal transition and reverses hypoxia-induced chemotherapy resistance in hepatocellular carcinoma cells. Am J Transl Res 9: 2608-2617, 2017. 
116. Chow AK, Yau TC, Ng L, Chu AC, Law WL, Poon RT and Pang RW: A preclinical study on the combination therapy of everolimus and transarterial chemoembolization in hepatocellular carcinoma. Am J Cancer Res 5: 2376-2386, 2015.

117. Li C, Wu X, Zhang H, Yang G, Hao M, Sheng S, Sun Y, Long J, $\mathrm{Hu} \mathrm{C}$, Sun X, et al: A Huaier polysaccharide restrains hepatocellular carcinoma growth and metastasis by suppression angiogenesis. Int J Biol Macromol 75: 115-120, 2015.

118. Wu J, Contratto M, Shanbhogue KP, Manji GA, O'Neil BH, Noonan A, Tudor R and Lee R: Evaluation of a locked nucleic acid form of antisense oligo targeting HIF-1 $\alpha$ in advanced hepatocellular carcinoma. World J Clin Oncol 10: 149-160, 2019.

119. Rapisarda A, Uranchimeg B, Sordet O, Pommier Y Shoemaker RH and Melillo G: Topoisomerase I-mediated inhibition of hypoxia-inducible factor 1: Mechanism and therapeutic implications. Cancer Res 64: 1475-1482, 2004.

120.Zhang C, Yang C, Feldman MJ, Wang H, Pang Y, Maggio DM, Zhu D, Nesvick CL, Dmitriev P, Bullova P, et al: Vorinostat suppresses hypoxia signaling by modulating nuclear translocation of hypoxia inducible factor 1 alpha. Oncotarget 8 : 56110-56125, 2017.

121. Li YL, Zhang NY, Hu X, Chen JL, Rao MJ, Wu LW, Li QY, Zhang B, Yan W and Zhang C: Evodiamine induces apoptosis and promotes hepatocellular carcinoma cell death induced by vorinostat via downregulating HIF-1 $\alpha$ under hypoxia. Biochem Biophys Res Commun 498: 481-486, 2018

122. Shao S, Duan W, Xu Q, Li X, Han L, Li W, Zhang D, Wang Z and Lei J: Curcumin suppresses hepatic stellate cell-induced hepatocarcinoma angiogenesis and invasion through downregulating CTGF. Oxid Med Cell Longev 2019: 8148510, 2019.

123. Xia Y, Choi HK and Lee K: Recent advances in hypoxia-inducible factor (HIF)-1 inhibitors. Eur J Med Chem 49: 24-40, 2012

124. Abu-Remaileh M, Khalaileh A, Pikarsky E and Aqeilan RI: Author Correction: WWOX controls hepatic HIF1 $\alpha$ to suppress hepatocyte proliferation and neoplasia. Cell Death Dis 9: 1159, 2018.

125. Yang Q, Guo X and Yang L: Metformin enhances the effect of regorafenib and inhibits recurrence and metastasis of hepatic carcinoma after liver resection via regulating expression of hypoxia inducible factors $2 \alpha$ (HIF-2 $\alpha$ ) and $30 \mathrm{kDa}$ HIV tat-interacting protein (TIP30). Med Sci Monit 24: 2225-2234, 2018.

126. Wada H, Nagano H, Yamamoto H, Yang Y, Kondo M, Ota H, Nakamura M, Yoshioka S, Kato H, Damdinsuren B, et al: Expression pattern of angiogenic factors and prognosis after hepatic resection in hepatocellular carcinoma: Importance of angiopoietin-2 and hypoxia-induced factor-1 alpha. Liver Int 26: 414-423, 2006.

127. Dai CX, Gao Q, Qiu SJ, Ju MJ, Cai MY, Xu YF, Zhou J, Zhang BH and Fan J: Hypoxia-inducible factor-1 alpha, in association with inflammation, angiogenesis and MYC, is a critical prognostic factor in patients with HCC after surgery. BMC Cancer 9: 418, 2009.

128. Xia L, Mo P, Huang W, Zhang L, Wang Y, Zhu H, Tian D, Liu J, Chen Z, Zhang Y, et al: The TNF- $\alpha /$ ROS/HIF-1-induced upregulation of FoxMI expression promotes HCC proliferation and resistance to apoptosis. Carcinogenesis 33: 2250-2259, 2012
129. Xiang ZL, Zeng ZC, Fan J, Tang ZY, He J, Zeng HY and Chang JY: The expression of HIF-1 $\alpha$ in primary hepatocellular carcinoma and its correlation with radiotherapy response and clinical outcome. Mol Biol Rep 39: 2021-2029, 2012.

130. Zheng SS, Chen XH, Yin X and Zhang BH: Prognostic significance of HIF-1 $\alpha$ expression in hepatocellular carcinoma: A meta-analysis. PLoS One 8: e65753, 2013.

131. Wang B, Ding YM, Fan P, Wang B, Xu JH and Wang WX: Expression and significance of MMP2 and HIF-1 $\alpha$ in hepatocellular carcinoma. Oncol Lett 8: 539-546, 2014.

132. Cao S, Yang S, Wu C, Wang Y, Jiang J and Lu Z: Protein expression of hypoxia-inducible factor-1 alpha and hepatocellular carcinoma: A systematic review with meta-analysis. Clin Res Hepatol Gastroenterol 38: 598-603, 2014

133. Liu LP, Hu BG, Ye C, Ho RL, Chen GG and Lai PB: HBx mutants differentially affect the activation of hypoxia-inducible factor- $1 \alpha$ in hepatocellular carcinoma. Br J Cancer 110: 1066-1073, 2014.

134. Wang D, Zhang X, Lu Y, Wang X and Zhu L: Hypoxia inducible factor $1 \alpha$ in hepatocellular carcinoma with cirrhosis: Association with prognosis. Pathol Res Pract 214: 1987-1992, 2018.

135. Bangoura G, Liu Z, Qian Q, Jiang C, Yang G and Jing S: Prognostic significance of HIF-2alpha/EPAS1 expression in hepatocellular carcinoma. World J Gastroenterol 13: 3176-3182, 2007.

136. Sun HX, Xu Y, Yang XR, Wang WM, Bai H, Shi RY, Nayar SK, Devbhandari RP, He YZ, Zhu QF, et al: Hypoxia inducible factor 2 alpha inhibits hepatocellular carcinoma grow th through the transcription factor dimerization partner $3 / \mathrm{E} 2 \mathrm{~F}$ transcription factor 1-dependent apoptotic pathway. Hepatology 57 1088-1097, 2013.

137. Yao Q, Lv Y, Pan T, Liu Y, Ma J and Xu G: Prognostic significance and clinicopathological features of hypoxic inducible factor-2alpha expression in hepatocellular carcinoma. Saudi Med J 36: 170-175, 2015.

138. Yang SL, Liu LP, Niu L, Sun YF, Yang XR, Fan J, Ren JW, Chen GG and Lai PB: Downregulation and pro-apoptotic effect of hypoxia-inducible factor 2 alpha in hepatocellular carcinoma. Oncotarget 7: 34571-34581, 2016.

139. Jiang L, Liu QL, Liang QL, Zhang HJ, Ou WT and Yuan GL: Association of PHD3 and HIF2 $\alpha$ gene expression with clinicopathological characteristics in human hepatocellular carcinoma. Oncol Lett 15: 545-551, 2018

140. Liu P, Fang X, Song Y, Jiang JX, He QJ and Liu XJ: Expression of hypoxia-inducible factor $3 \alpha$ in hepatocellular carcinoma and its association with other hypoxia-inducible factors. Exp Ther Med 11: 2470-2476, 2016.

This work is licensed under a Creative Commons Attribution-NonCommercial-NoDerivatives 4.0 International (CC BY-NC-ND 4.0) License. 